\title{
PREDICTION OF CAVITATION ON KAPLAN TURBINES USING FUZZY LOGIC MODELLING
}

\author{
Abdullah Mohammed Adam \\ Ph.D. Student, Faculty of Post Graduates, Nile Valley University, Atbara, Sudan \\ Fath Elrahman Elmahi \\ Professor, Faculty of Mechanical Engineering, Nile Valley University, Atbara, Sudan \\ M.I. Shukri \\ Professor, Faculty of Post Graduates, Nile Valley University, Atbara, Sudan
}

\begin{abstract}
ABSTRASCT: Cavitation is a serious problem causes surface erosion in hydraulic turbines as a result of evaporation and condensation of water due to pressure change, it typically causes noise, vibration and finally limits the operating range of the turbine, The present paper deals with a numerical method for prediction of cavitation damage level on Kaplan turbines. A method was applied to predict the intensity of cavitation damage to using the Fuzzy Logic System. Five levels of damage intensity were considered to predict cavitation damage in the Kaplan turbines of Rosaries Dam in Sudan. According to the results, the proposed model could properly predict the intensity of cavitation damage in comparison with the actual reports in the past critical periods, flood season, water restriction and black out times. The fuzzy logic (Mamadani system) is applied with aid of MATLAB in three input cases, first is for cavitation index only, second is for flow velocity only, and finally is the combination of both cavitation index and flow velocity governed by 25 (AND) intersection rules. Two output results could be gained into two formats one is a (2D) rule viewer and the other is (3D) surface viewer from which a decision making can be taken after converting the output linguistic terms into crisp, efficient and suitable values.
\end{abstract}

Keywords: Cavitation Levels; Kaplan Turbines; Fuzzy logic model; Cavitation Prediction.

\section{INTRODUCTION}

Cavitation can produce holes and damage in hydraulic structures. Sometimes in a hydraulic system local pressure decreases and probably reaches to fluid vapor pressure because of high velocity. Also due to surface roughness, stream lines separate from their bed and local pressure reduces to the vapour pressure. Therefore in the disruption of continuity in the liquid, fluid boils and the vapour bubble is formed. These vapour bubbles (or cavities) after collapsing generate shock waves that produce high impact forces on adjacent surfaces and cause work hardening, fatigue and cavitation pits.
In Kaplan turbines the velocity is considerably high, hence small roughness in millimetres can produce cavitation. The damage in some structures is so severe, that it hardly can function unsafely and properly again with repairing.

Based on the researchers' many years of investigations it proved that the process of cavitation damage is very complex due to various factors, and their interaction, influences on cavitation damage. The investigations and the result of prototypes lead to a traditional method using cavitation index dependent on pressure and velocity to prevent cavitation. In this method the aim is to reach an index bigger than the critical cavitation index (Fatema

Zandi et al. 2014). The following function is used to achieve the cavitation index in flow. $\sigma>\sigma_{\mathrm{c}}$ The following function is used to achieve the cavitation index in flow.

$\sigma=\frac{H_{a t m}-H_{v}-H_{S}}{H_{n e t}}$

Where, $\mathrm{H}_{\text {atm }}$ is atmospheric head in $\mathrm{m}, \mathrm{H}_{\mathrm{s}}$ is suction pressure at the outlet of reaction turbine, $\mathrm{H}_{\mathrm{v}}$ is a vapour pressure and $H_{\text {net }}$ is a net head in m.(Rajput R.K. 2009) .

As cavitation damage has been one of the major engineering concerns about water turbines, many efforts have been made to verify the damage mechanism. (Munendra Kumar et al. 2015) (Ryo Amano et al. 2017) have investigated cavitation damage occurrence on water turbines using experimental modeling under controlled laboratory conditions. Moreover, numerical modelling such as: (Bernd Nennemann et al 2007) (Sulo Lhdelma et al. 2007) have successfully investigated flow characteristics and cavitation formation.

Fuzzy logic was used to predict the intensity of cavitation through different components of Kaplan turbines, fuzzy membership functions for two input data sets (flow velocity and cavitation index) are to be assigned to different categories and different periods of operation.

Five levels of cavitation intensity will be considered as an output of fuzzy rules to predict the cavitation in the most affected regions. Fuzzy inference system will be calculated and prepared by aid of (MATLAB) to give précised and efficient results. The cavitation indices will be considered over all generated models with real dimensions and variables. 
International Journal of Engineering Applied Sciences and Technology, 2020

Vol. 5, Issue 8, ISSN No. 2455-2143, Pages 76-81

Published Online December 2020 in IJEAST (http://www.ijeast.com)

II. FUZZY LOGIC MODEL DESCRIPTION

The application of fuzzy logic consists of three stages.

Figure (1) shows the methodology of fuzzy logic.

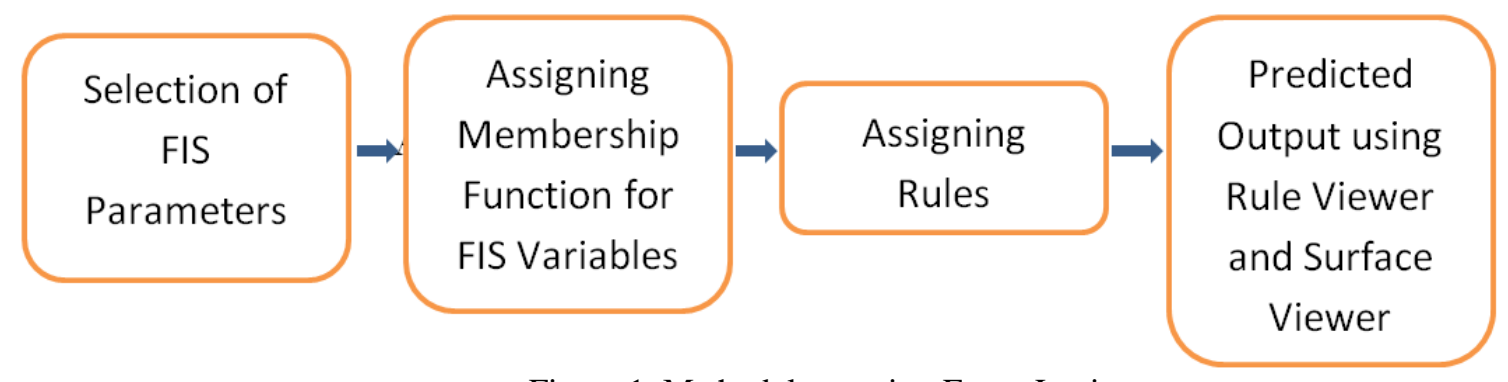

Figure 1. Methodology using Fuzzy Logic

(i) Fuzzy rule base design:

The fuzzy rule base design consists of five steps:

Step: 1: Compose a list of input and output variables by means of operator. In this paper there are two input variables and one output variable, The output variable is a predicted cavitation and the input variables are:

a) Cavitation Index,

b) Flow Velocity.

Step: 2: The input and output variables are prepared by resolving the input and output performance to the membership value of range $\left[\begin{array}{llllllll}0 & 0.1 & 0.2 & 0.3 & 0.4 & 0.5 & 0.6 & 0.7\end{array}\right.$ $\left.\begin{array}{lll}0.8 & 0.9 & 1\end{array}\right]$.

Step: 3: After resolving the input and output variables now select the character of fuzzy membership for each of the variable.

Step: 4: For each input and output variable, number of fuzzy membership function has to be defined.

Cavitation index data when fuzzified classifies into five fuzzy sets as:
(i) Very small,
(v) Very big.
(ii) Small,
(iii) Normal,
(iv) Big

Table 1: Input Membership Function Values for Cavitation Index

\begin{tabular}{|l|l|llll|}
\hline Cavitation Index & Type of Membership Function & \multicolumn{4}{l|}{ Values } \\
\hline Fuzzy Set & Trapezoidal & $\sigma_{0}$ & $\sigma_{0}$ & $\sigma_{0.2}$ & $\sigma_{0.4}$ \\
\hline Very Small & Triangular & $\sigma_{0.2}$ & $\sigma_{0.4}$ & $\sigma_{0.6}$ & \\
\hline Small & Triangular & $\sigma_{0.4}$ & $\sigma_{0.6}$ & $\sigma_{0.8}$ & \\
\hline Normal & Triangular & $\sigma_{0.6}$ & $\sigma_{0.8}$ & $\sigma_{1}$ & \\
\hline Big & Trapezoidal & $\sigma_{0.8}$ & $\sigma_{1}$ & $\sigma_{1.2}$ & $\sigma_{1.2}$ \\
\hline Very Big & & & & & \\
\hline
\end{tabular}

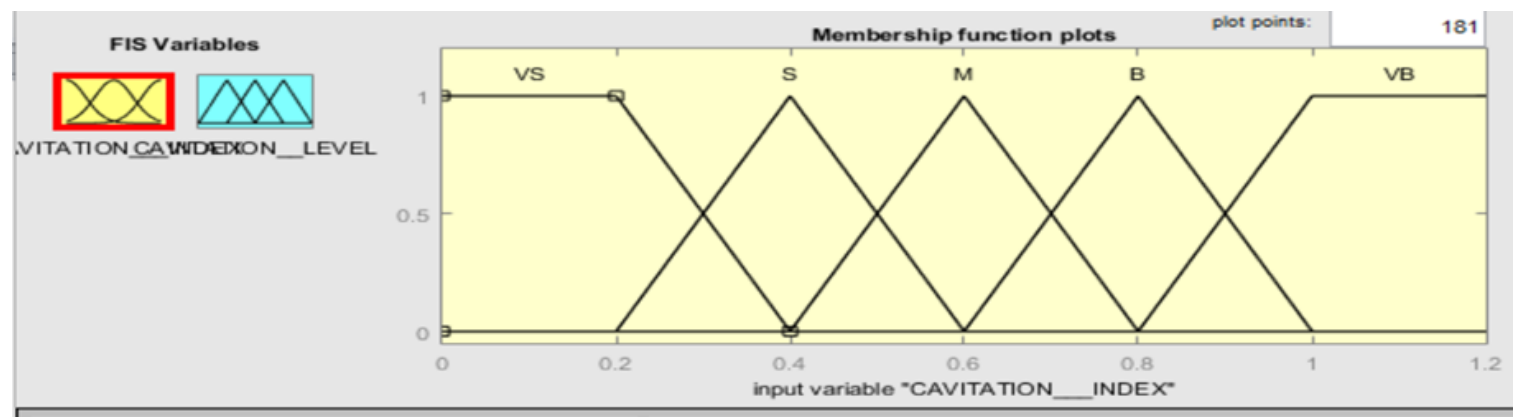

Figure 2 : Fuzzy Set for Input 1 (Cavitation Index)

Flow velocity data when fuzzified classifies into five fuzzy sets as:
(i) very low
(ii) low
(iii) normal
(iv) high
(v) very high

Table 2: Input Membership Function Values for Flow velocity

\begin{tabular}{|l|l|l|}
\hline Flow Velocity & Type of Membership Function & Values \\
\hline Fuzzy Set & Trapezoidal & $\mathrm{v}_{0} \quad \mathrm{v}_{0} \quad \mathrm{v}_{2} \quad \mathrm{v}_{4}$ \\
\hline Very Low & Triangular & $\mathrm{v}_{2} \quad \mathrm{v}_{4} \quad \mathrm{v}_{6}$ \\
\hline Low & Triangular & $\mathrm{v}_{4} \quad \mathrm{v}_{6} \quad \mathrm{v}_{8}$ \\
\hline Normal & $\mathrm{v}_{6} \quad \mathrm{v}_{8} \quad \mathrm{v}_{10}$ \\
\hline High & Triangular & $\mathrm{v}_{8} \quad \mathrm{v}_{10} \quad \mathrm{v}_{12} \quad \mathrm{v}_{12}$ \\
\hline Very High & Trapezoidal & \\
\hline
\end{tabular}


International Journal of Engineering Applied Sciences and Technology, 2020

Vol. 5, Issue 8, ISSN No. 2455-2143, Pages 76-81

Published Online December 2020 in IJEAST (http://www.ijeast.com)

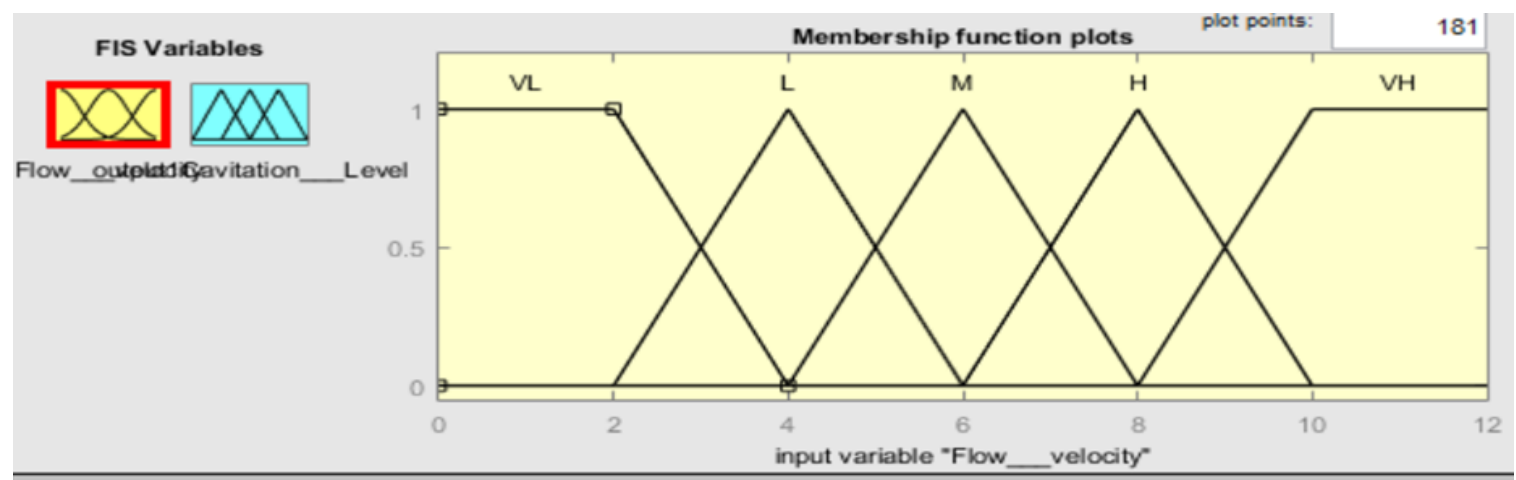

Figure 3 : Fuzzy Set for Input2 (Flow velocity)

Flow velocity and cavitation index data are two inputs taken for the cavitation damage levels as shown in Figure.4. Cavitation levels are divided into five fuzzy sets:

i-Very light ii- Light, iii- Normal, iv-Serious, v- Major.

Table 3 : Output Membership Function Values for Cavitation Levels

\begin{tabular}{|l|l|l|l|}
\hline Cavitation Level & Type of Membership Function & Values \\
\hline Fuzzy Set & Triangular & $\mathrm{L}_{0} \quad \mathrm{~L}_{0.15} \quad \mathrm{~L}_{0.3}$ \\
\hline Very Light & Triangular & $\mathrm{L}_{0.1} \quad \mathrm{~L}_{0.3} \quad \mathrm{~L}_{0.5}$ \\
\hline Light & Triangular & $\mathrm{L}_{0.3} \quad \mathrm{~L}_{0.5} \quad \mathrm{~L}_{0.7}$ \\
\hline Normal & Triangular & $\mathrm{L}_{0.5} \quad \mathrm{~L}_{0.7} \quad \mathrm{~L}_{0.9}$ \\
\hline Serious & $\mathrm{L}_{0.7} \quad \mathrm{~L}_{0.85} \quad \mathrm{~L}_{1}$ \\
\hline Major & Triangular &
\end{tabular}

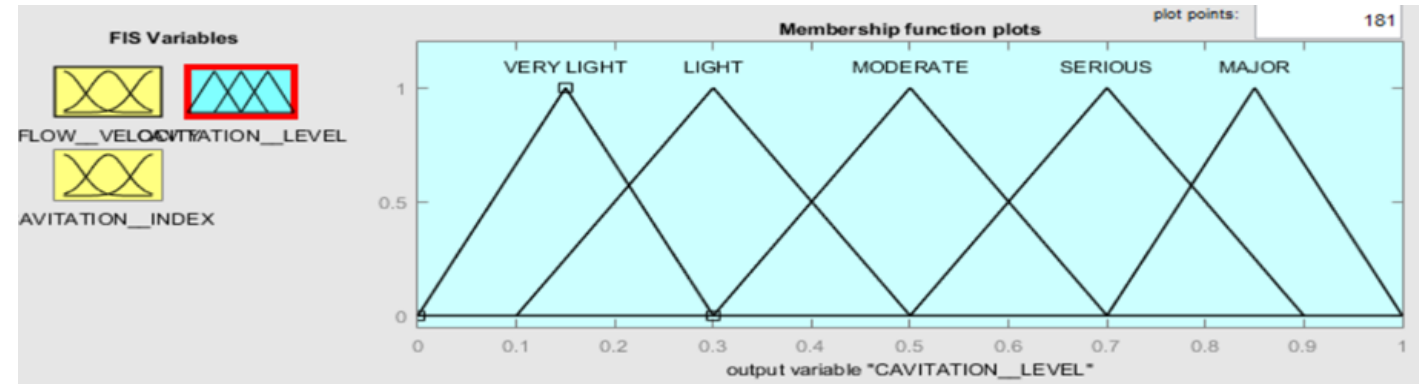

Figure 4 : Fuzzy Set for Output (Cavitation Damage Levels)

Step: 5: Now we have to train the data in fuzzy model. Training data can be inferred as pair of input data and output data. For e.g. if (cavitation index) is very small and, flow velocity $^{\mathrm{ee}}$ is very high, leading to major cavitation level. Computing the prediction value:

From input to output space a nonlinear surveying implements a fuzzy inference system. The surveying is done by a fuzzy If-Then rule.

To estimate the cavitation prediction from the fuzzy forecast then the defuzzification is performed. An analytical forecast to the entire rule is centre of area. $\mathrm{y}=\frac{\int \mu_{A}\left(y_{i}\right) * y_{i} d y}{\mu_{A}\left(y_{i}\right) d y}$

\section{A. FUZZIFICATION}

Method of conversion of the crisp values to the degree of membership in relation with the fuzzy set is known as fuzzification. The input and output might be non-linear but linear membership function is applied for the ease. In this paper triangular and trapezoidal membership functions are utilized for the input and output. Figure.2. represents how to create the FIS variables. 


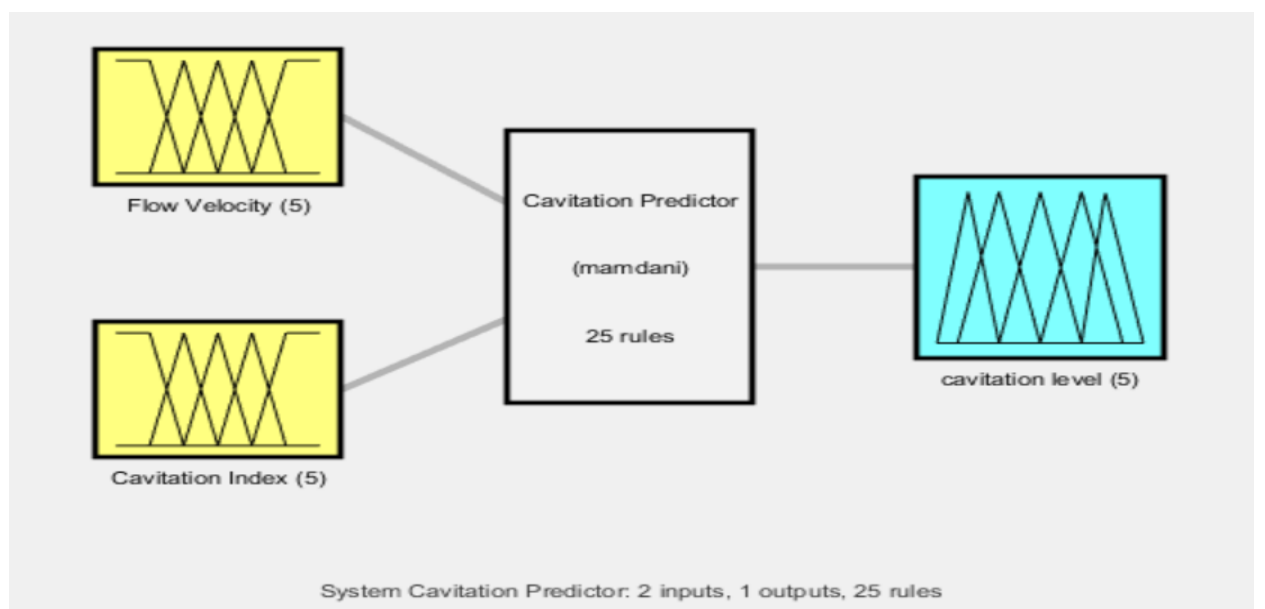

Figure.5. Creating FIS variables

\section{B. FUZZY RULE BASE}

The fuzzy system backbone is the fuzzy rule base. To get the predicted output in the fuzzy rule base, the If-Then rule is used. A few rules are shown in Figure.3. and Figure.4.

- If (flow velocity is very low) and (cavitation index is very small) then (cavitation level is normal).
- If (flow velocity is low) and (cavitation index is normal) then cavitation level is low

- If (flow velocity is normal) and (cavitation index is normal) then cavitation level is normal

- If (flow velocity is high) and (cavitation index is small) then (cavitation level is serious).

- If (flow velocity is low) and (cavitation index is big) then (output is very low).

Table 4. Assigning rules

\begin{tabular}{|l|l|l|l|l|l|}
\hline $\mathrm{V}$ & VS & S & N & B & VB \\
\hline VL & N & L & L & VL & VL \\
\hline L & N & N & L & VL & VL \\
\hline N & S & N & N & L & VL \\
\hline H & S & S & N & N & L \\
\hline VH & M & S & S & N & N \\
\hline
\end{tabular}

\section{PREDICTED OUTPUT CAVITATION LEVELS}

In this step, cavitation levels prediction is made by rule viewer and surface viewer. Refer Figure. 7 and 8.

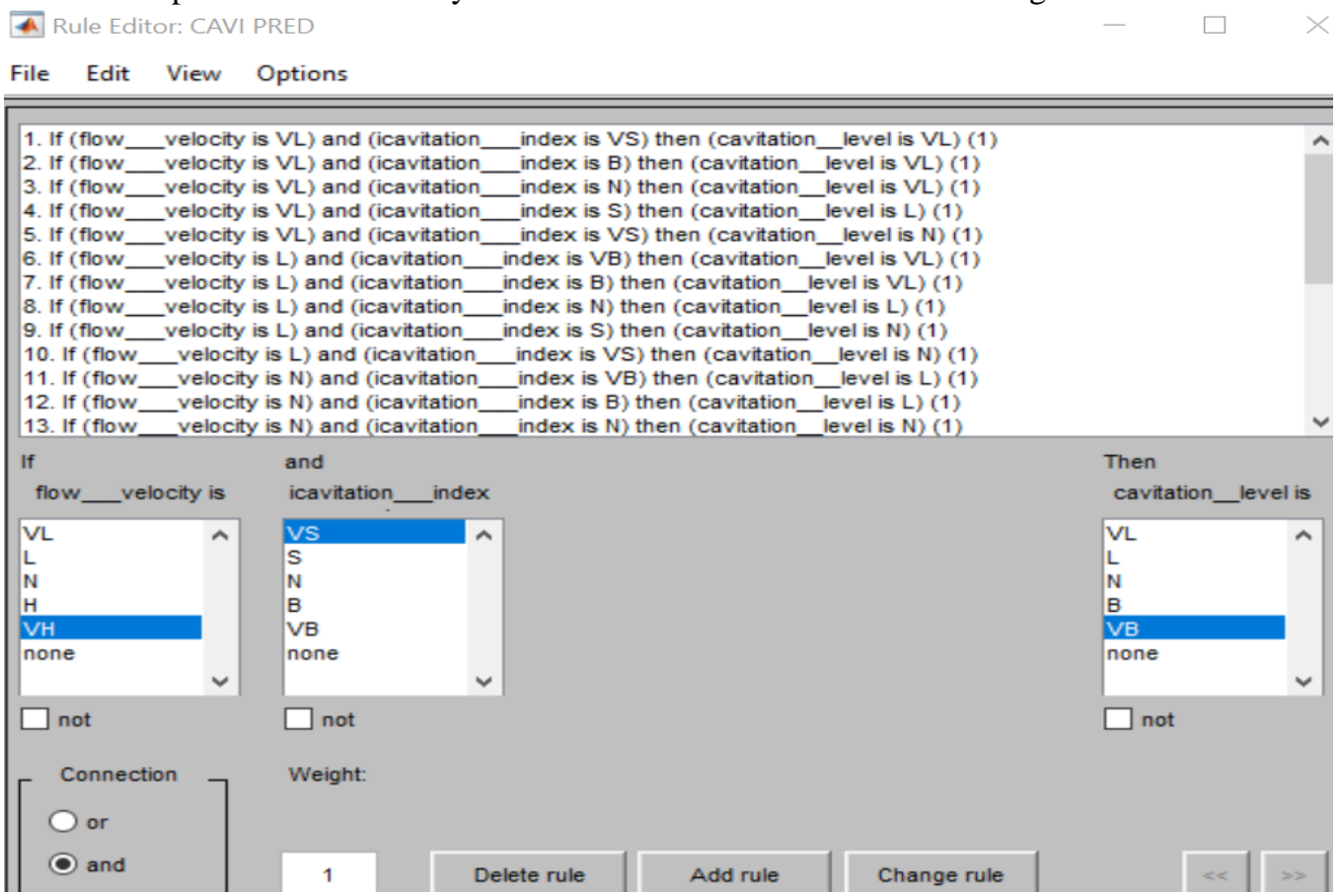

Figure.6. Fuzzy Rule Base 

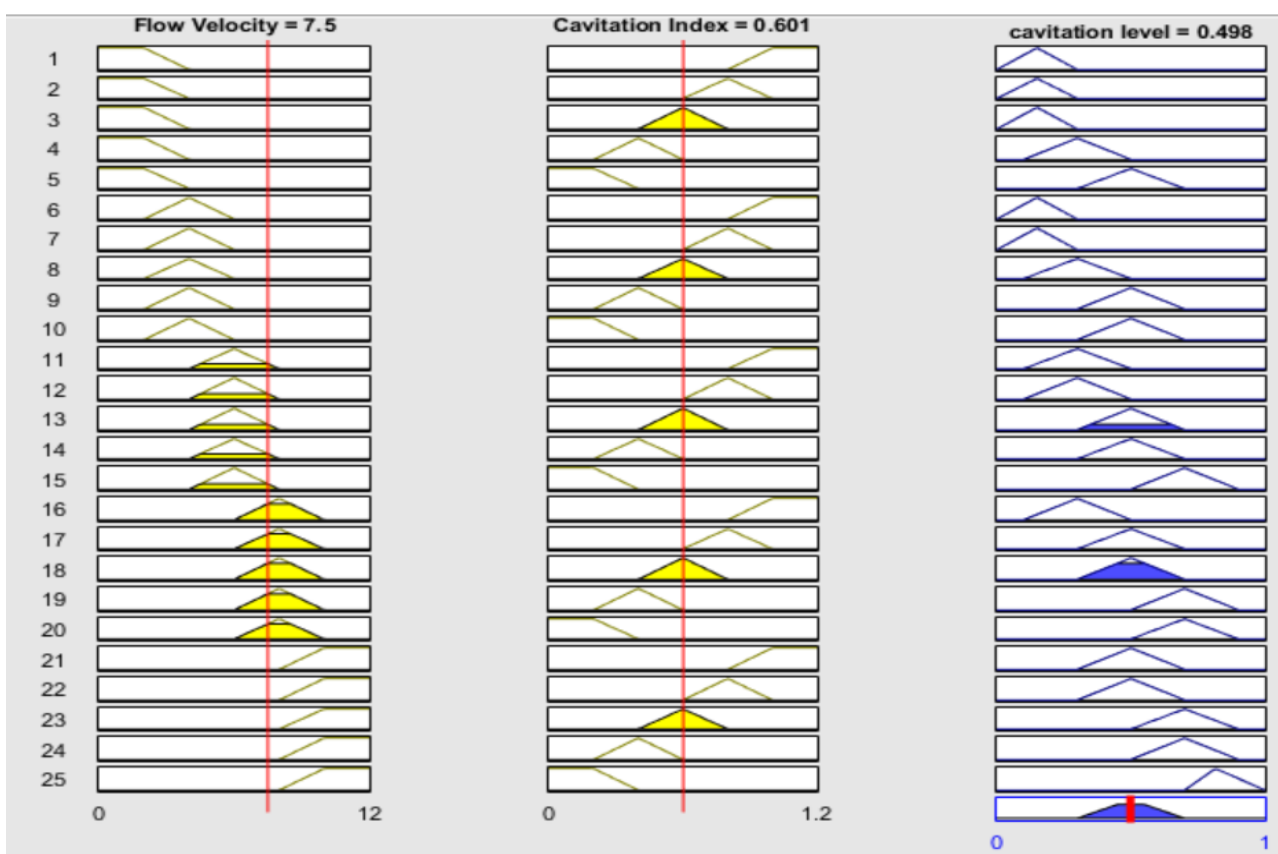

Figure.7. Predicted output cavitation level

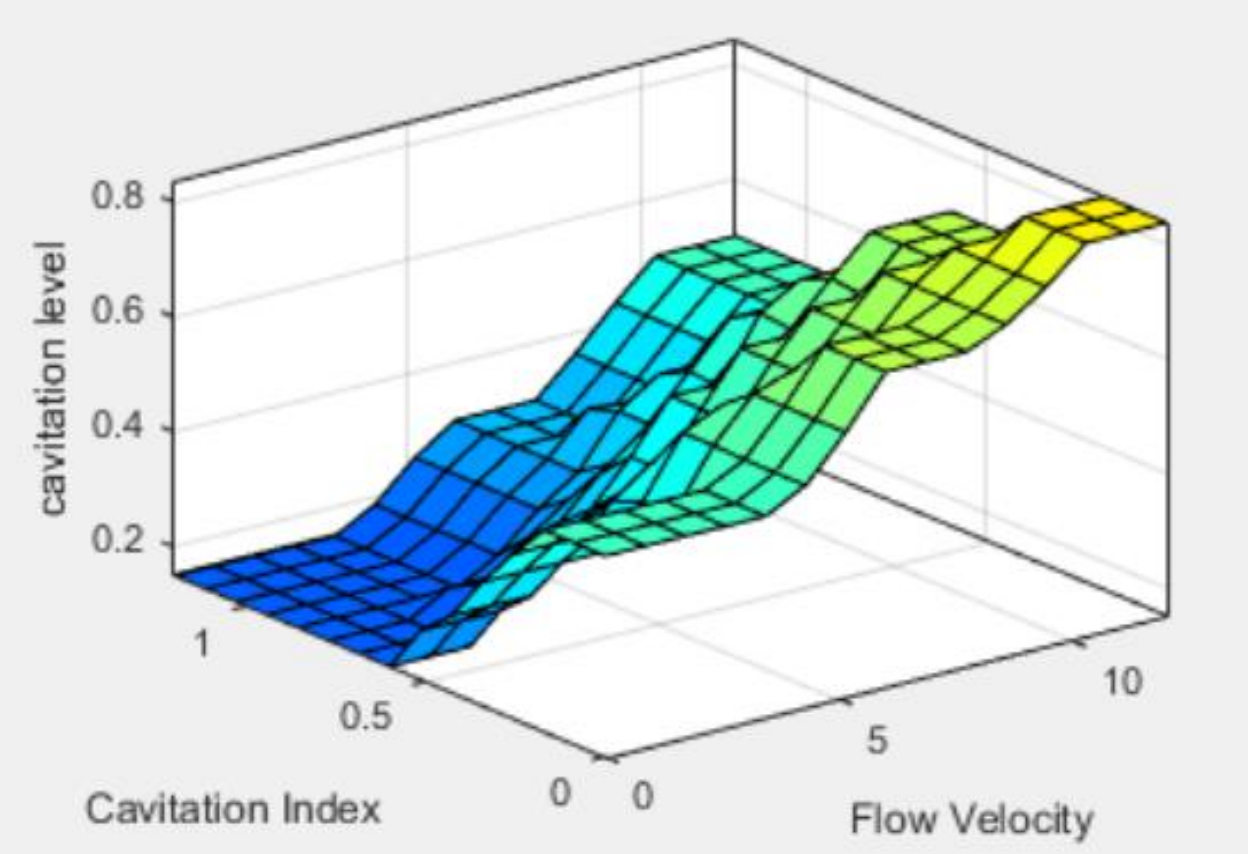

Figure.8. 3D output based on inputs

\section{CONCLUSION}

In this paper the author discuss about the prediction of cavitation in Kaplan turbines using fuzzy logic approach which ultimately helps in short term damage forecasting. From the results so obtained, it is observed that the application of fuzzy logic to predict the level of cavitation based upon the flow velocity and cavitation index is so accurate. Cavitation prediction can also help in better operation and maintenance management, improving power generation and efficiency decrease can be easily monitored. In the end, it can be safely concluded that the scope or applications of accurate cavitation prediction in Kaplan turbine are enormous.

From figure (8) we can summarize the cavitation levels in Kaplan when cavitation index and flow velocity are calculated, in the table below: 
International Journal of Engineering Applied Sciences and Technology, 2020

Vol. 5, Issue 8, ISSN No. 2455-2143, Pages 76-81

Published Online December 2020 in IJEAST (http://www.ijeast.com)

Table 5: cavitation levels in different flow velocity and cavitation index

\begin{tabular}{|r|r|r|}
\hline Flow Velocity $(\mathrm{m} / \mathrm{s})$ & Cavitation Index $(-)$ & Cavitation Level (-) \\
\hline Very high & Very small & major \\
\hline high & small & serious \\
\hline normal & normal & normal \\
\hline low & big & light \\
\hline Very low & Very big & Very light \\
\hline
\end{tabular}

\section{REFERENCES}

1. Munendra K., Alok N. (2015). Cavitation in Kaplan Turbines -A Review : Systematic literature review identified the best methods to prevent cavitation , Journal of Material Science and Mechanical Engineering, (p. 425-429).

2. Bernd N.,Thi C. VU (2007), Kaplan Turbine Blade and Discharge Ring Cavitation Prediction using Unsteady CFD: An Experimental Study on Kaplan Turbine, Paper presented at the Second International Meeting of the Workgroup on Cavitation and Dynamic Problems in Hydraulic Machinery and Systems, Timisoara, Romania.

3. Nihar T., Sanket C., (2015). Cavitation Detection in Hydraulic Machines: A Review used physical experiment, International Journal on Theoretical and Applied Research in Mechanical Engineering, ( $\mathrm{P}$. 47,48,49,51,52).

4. Fadaei E., Barani G.A and Ghaeini Hessaroeyeh M. (2017), Cavitation Damage Prediction on Dam Spillways using Fuzzy - KNN Modelling: Evaluated cavitation level and the region effected using nonparametric method, Journal of Applied Fluid Mechanics, (p. 323-329).

5. Jorg N., Carsten M. and Emad T. (2015). Cavitation Monitoring in Hydraulic Turbines: Technical support by the company staff, Voith Hydro Holding GMBH \& CO., Heiderheim, Germany, (p. 5,6,7).

6. Lotfi Zadeh A., (1965). Fuzzy Sets, Fuzzy Logic and Fuzzy Systems: Basic definitions about fuzzy Logic, Binghamton University, New York, USA. (P. 17 - 35).

7. Jaume Polo (2001). Development and Testing of Number of MATLAB Based Fuzzy System Applications : Thesis project, University of Warwick, (P. 20-27).

8. Fatema Z. G., Mehdi A. M. and Abbas P. (2014). Fuzzy Predicting Model for Cavitation in Chute Spillways : Systematic Literature Reviw, GJSR Journal. (p. 12-20).

9. Jimoh, R. G., Olagunju, M., Folorunso, I.O., and Asiribo, M.A. (2013). Modelling Rainfall Prediction using Fuzzy Logic: Applied Study to design prediction control, International Journal of Innovative Research in Computer and Communication Engineering, (p. 929 - 935).

10. Manish K. S., Harkamal D. K., and Parag N. (2019). Rain Prediction using Fuzzy Logic: Applied Study designed for short term load forecasting, International Journal of Engineering and Advanced Technology, (p. 2793 - 2796).
11. Rajput, R. K. (2009). Fluid Mechanics and Hydraulic Machines: Step by Step Hydraulic Machine Design, Chand S., New Delhi India, (p. 1052-1171).

12. Abeykoon, C., and Hantsch, T. (2017). Design and Analysis of a Kaplan Turbine Runner Wheel: Paper presented In The 3rd World Congress on Mechanical, Chemical, and Material Engineering, Rome, Italy, (p. 1-16).

13- Kevin Simon Boddeus (1999). Cavitation in Valve : PHD Thesis project, University of Wollongong, (p 28 $-34)$.

14- Remi A. S. (2011). Testing efficiency and characteristics of a Kaplan-type small turbine: Project Thesis, Norwegian University of Science and Technology.

15- Fukaya (2010). Prediction of Cavitation Intensity and Erosion Area in Centrifugal Pump by Using Cavitating Flow Simulation with Bubble Flow Model : literature Review, Journal of Fluid Science and Technology, (p. 305-316). 